упомянутых выше предприятия, промзоны которых и прилегающие территории должны подвергаться регулярному детальному обследованию почв в масштабе 1:10000 на специфические для них металлы $\mathrm{Cd}, \mathrm{Ni}, \mathrm{Pb}$. На остальной территории, как показывает опыт, можно ограничиться выборочными обследованиями почв через 5-6 лет. Тем не менее представляется оправданным смещение акцента на снеговую съёмку, результаты которой дают важную информацию о загрязнении природной среды в реальном режиме времени. Для получения информации о наличии тяжелых металлов снеговую съёмку можно проводить только в зонах заводов «Электроисточник» и ЗАИТ и их промышленных площадок. В общегородском масштабе номенклатура загрязнителей, подлежащих определению, должна быть пополнена нефтепродуктами, фенолом и рядом других специфических веществ.

\section{Библиографический список}

1. Макаров В.3. Ландшафтно-экологический анализ крупного промышленного города / Под ред. Ю.П. Селивёрстова. Саратов: Изд-во Сарат. ун-та, 2001.

2. Чумаченко А.Н. Эколого-географическое картографирование городов // Взаимодействие картографии и геоинформатики. М.: Научный мир, 2000.

3. Макаров В.3., Новаковский Б.А., Чумаченко А.Н. Эколого-географическое картографирование городов. М.: Научный мир, 2002.

4. О состоянии окружающей природной среды Саратовской области в 1997 году. Саратов, 1998.

5. Форма нахождения тяжёлых металлов в почвах г. Саратова и природоохранные решения / Ред. кол. С.П. Балашова и др. Саратов: Научная книга, 2001.

УДК [004:504:553.98] (470.44)

\title{
ПРИМЕНЕНИЕ ГИС-ТЕХНОЛОГИЙ ПРИ ОЦЕНКЕ СТЕПЕНИ УСТОЙЧИВОСТИ ТЕРРИТОРИИ К ЗАГРЯЗНЕНИЮ НЕФТЬЮ И НЕФТЕПРОДУКТАМИ (На ПрИМере районов промышленной добычи нефти в Саратовской области)
}

\section{А.В. Молочко}

Саратовский государственный университет, кафедра геоморфологии и геоэкологии E-mail: farik26@yandex.ru

Проведенное районирование территории промышленной нефтедобычи в Саратовской области с использованием геоинформационных технологий дает возможность выделять в рамках района исследования ареалы с разной устойчивостью к нефтяному загрязнению в зависимости от их принадлежности к типу местности и природной зоне.

Ключевые слова: добыча нефти, Саратовская область, устойчивость территории, нефтяное загрязнение, геоинформационные системы.

Regionalization of Saratov Region commercial Oil Production Region according the Territory resistance of Oil Pollution with GIS Supporting

\section{A.V. Molochko}

The regionalization of Saratov region commercial oil production region supporting with GIS is made possible to mark out (within the research region) several areas with different resistance to oil pollution subject to area types and native zones.

Key words: commercial oil production, Saratov region, territory resistance, oil pollution, GIS.

С каждым годом ухудшающееся геоэкологическое состояние Саратовской области при-



водит к необходимости проведения мер по его стабилизации и возможному улучшению, а также выявлению территорий, наиболее подверженных геоэкологическому риску. Поскольку нефтяная отрасль выступает одним из источников подобных рисков, проблема районирования территории промышленной нефтедобычи становится одним из наиболее важных вопросов в решении геоэкологических задач [1]. Для решения подобных задач целесообразно использование современных геоинформационных технологий, позволяющих существенно усовершенствовать процессы сбора, моделирования и визуализации геоэкологической информации, построения на основе ее обработки прогноза развития ситуации и выработке рекомендаций по дальнейшему использованию территорий.

Нефтедобывающая отрасль по суммарному годовому риску возникновения аварийных разливов нефти и нефтепродуктов, а также возникновению чрезвычайных ситуаций, способных привести к существенному влиянию на окружающую природную среду и человека, занимает одно из первых мест среди всех отраслей материального производства [2]. Нефтяная отрасль Саратовской области не является исключением.

Нефтедобывающая отрасль в Саратовской области существует уже более 55 лет. В настоящее время ежегодная добыча нефти в области составляет более 1400 тыс. т [3]. Основным до- 
бывающим предприятием является ОАО «Саратовнефтегаз» [4].

Несмотря на существенные перспективные запасы углеводородного сырья, промышленная добыча территориально сосредоточена лишь в нескольких районах области - Саратовском, Татищевском, Лысогорском, Красноармейском, Энгельсском, Ровенском, Советском, Новобурасском и Базарно-Карабулакском [1].

Способность территории противостоять нефтяному загрязнению (показатель устойчивости) основывается на самовосстановлении и саморегуляции природных комплексов, способных по-разному противостоять антропогенным воздействиям и сохранять свои свойства [5].

Природные зоны и подзоны, а также входящие в их состав ландшафтные районы характеризуются различными зональными, гидроклиматическими, ботаническими, почвенными характеристиками и, соответственно, обладают различной экологической устойчивостью и способностью к самоочищению и самовосстановлению [6].

Степень распространения и влияния нефтяного загрязнения на территорию в большей степени зависит от приуроченности месторождений к различным типам местности, а также природным подзонам с характерными для них климатическими условиями, особенностями растительного и почвенного покрова, степенью проявления экзогенных геологических процессов, рельефом и т.д. [5].

Условно, по генезису, на изучаемой территории промышленной нефтедобычи можно выделить пойменные, террасовые, долинный, склоновые и приводорадельные типы местности (рис. 1).

В связи с климатическими, орографическими и гипсометрическими особенностями территории логично будет вести речь отдельно о правобережных и левобережных районах

\section{Левобережье Саратовской области}

В Левобережном районе выделяются Приволжский район (включающий в себя волжские террасы и пойму) и район Низкой Сыртовой равнины (захватывающий всю остальную территорию левобережной части области в границах района промышленной нефтедобычи).

Приволжский район левобережного региона промышленной нефтедобычи.

Этот район, тянущийся вдоль левого берега Волгоградского водохранилища, является наиболее уязвимым в геоэкологическом отношении. Он охватывает месторождения, расположенные на волжских террасах и формирующейся пойме.

Низкая и высокая поймы р. Волги на исследуемой территории района промышленной нефтедобычи полностью затоплены водами Волгоградского водохранилища $[7,8]$. Однако за счет активной работы водного потока идет фор- мирование новой высокой поймы, сложенной песчаными аккумулятивными отложениями на месте первой надпойменной террасы. Поэтому в данной статье первая надпойменная терраса и формирующаяся высокая пойма будут считаться синонимами. Высокая формирующаяся пойма выражена не везде [9]. Абсолютные отметки высоты колеблются от 20-25 м на севере до 5-6 м на юге. В период весеннего половодья пойменная часть водохранилища ежегодно затапливается водой. Более того, поверхность формирующейся высокой поймы отличается большим количеством стариц, небольших проток. Весеннее половодье, близость грунтовых вод, легкий механический состав почв и грунтов, уклон территории, активные оползневые и абразионные процессы создают на пойме благоприятные условия для проникновения загрязняющих веществ в поверхностные и подземные воды, а скорость течения, преобладающее направление ветра и время года - для распространения нефтяного пятна по акватории водоема.

Террасовый тип местности характерен для палеотеррас р. Волги. Волжские палеотеррасы в зоне промышленной нефтедобычи представлены второй и третьей хвалынскими и четвертой хазарской террасами $[7,8,9]$. Вторая надпойменная терраса практически повсеместно прослеживается на левом берегу р. Волги. Абсолютные высоты ее в северной части достигают 37 м, снижаясь к югу до 25 м. Терраса в основном сложена песками, суглинками и супесями, которые в редких участках бронированы шоколадными глинами. Третья надпойменная терраса прослеживается на отметках 30-55 м. Она сложена рыхлыми отложениями (песками и супесями). Грунтовые воды повсеместно расположены на небольшой глубине и способствуют быстрой инфильтрации возможного загрязнения через почвы легкого механического состава. Четвертая надпойменная терраса представлена озерно-аллювиальными отложениями. Ее высотное положение составляет 60 м и выше.

К Приволжскому району относится основное число месторождений, располагающихся в 2 различных типах ландшафтов: северная часть - в типично степном низменном слаборасчлененном ландшафтном районе волжских пойменных террас на глинистых, суглинистых темно-каштановых почвах под типчаковоковыльными степями и сельхозугодьями на них $[10,11]$; южная часть - в сухостепном низменном слаборасчлененном ландшафтном районе Низкого Сыртового Заволжья с суглинистыми каштановыми почвами под типчаковоковыльными ассоциациями, а также на солонцеватых светло-каштановых почвах и солонцах под полынно-злаковыми ассоциациями.

Основное влияние на степень устойчивости данной территории к нефтяному загрязнению 


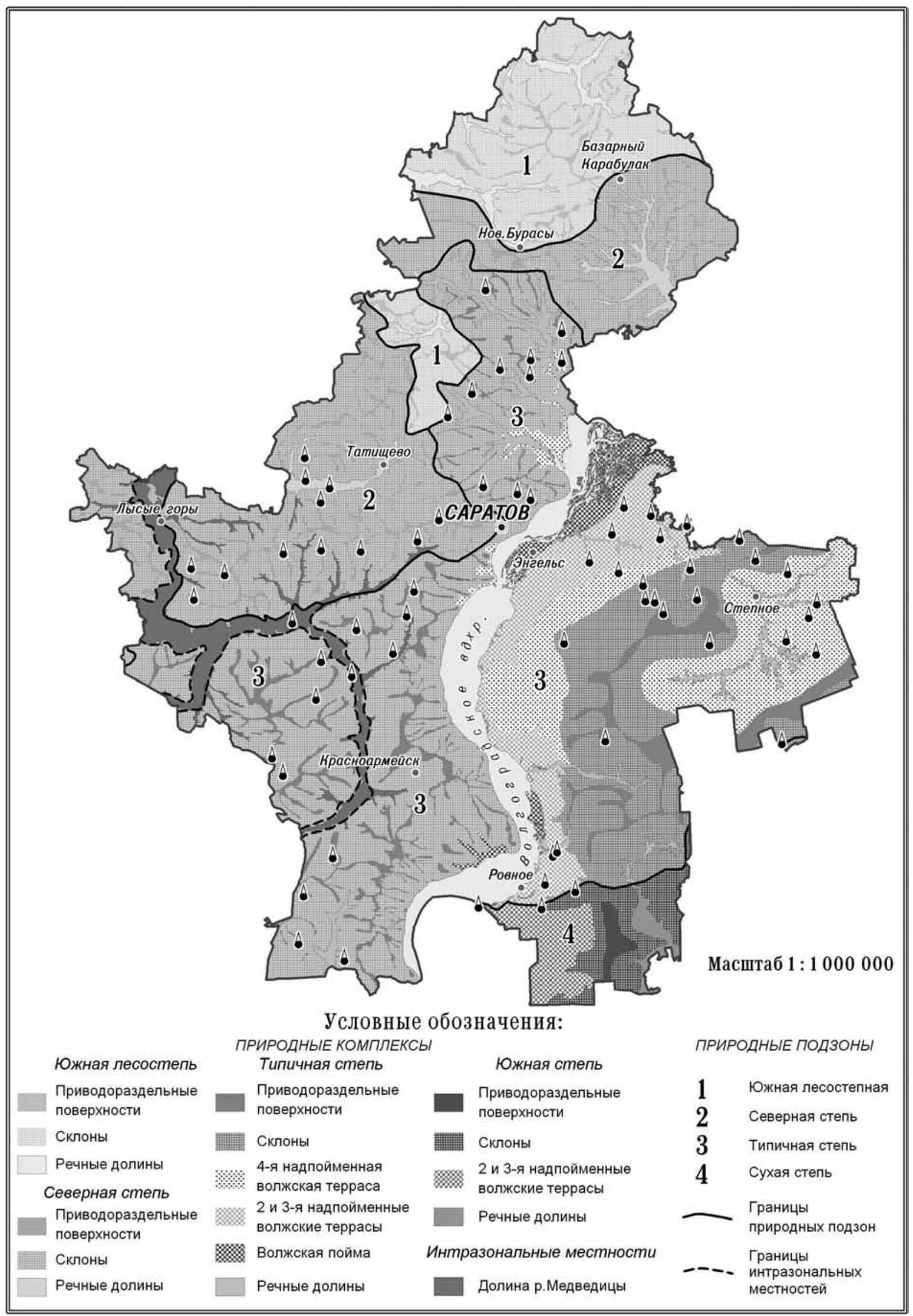

Рис. 1. Типы местности района промышленной добычи нефти и нефтепродуктов в Саратовской области 
будут оказывать следующие факторы: вопервых, прибрежное положение территории по отношению к Волгоградскому водохранилищу с риском подтопления в период половодья; вовторых, наличие плоскостного смыва ввиду слабой расчлененности рельефа [12]; в-третьих, засоление почвы, которое является существенным фактором риска повышения коррозийных свойств почв; в-четвертых, смена ландшафтных районов с типичной степи на сухую степь, изменение типов почв с темно-каштановых (относительно плодородных) на светло-каштановые и солонцы $[11,13]$. Уменьшение разнообразия растительного покрова выступает существенным фактором геоэкологического риска, поскольку в сухой подзоне всегда будут преобладать процессы концентрации загрязнителей или продуктов их нейтрализации.

При оценке устойчивости природных комплексов к нефтяному загрязнению особое значение имеют свойства почв. Почвы могут выполнять защитную роль по отношению к природным водам, атмосфере и растительности [5, 14]. Например, гумусовые горизонты являются геохимическими барьерами, в которых накапливаются нефтепродукты и легкорастворимые соли, не проникая в глубь почвенного профиля. При анализе северной и южной частей района была выявлена тенденция к сокращению толщины гумусового слоя в почвенном профиле от темно-каштановых почв к светло-каштановым и солонцам.

Район Низкой Сыртовой равнины охватывает меньшее количество месторождений. В основном это южный вариант подзоны типичной степи. Почвы здесь темно-каштановые с пятнами южных черноземов на водоразделах. Преобладает типчаково-ковыльная степь с ксерофитным разнотравьем [11]. Данный район более устойчивый к нефтяному загрязнению чем предыдущий, поскольку основная часть месторождений расположена либо на приводораздельных поверхностях, либо на переходных между приводораздельных к склоновым, либо на пологих склонах Низкой Сыртовой равнины.

\section{Правобережье Саратовской области}

Для правобережных районов, в отличие от Заволжья, характерны более значимые отметки высот, связанные с расположением территории на восточных отрогах Приволжской возвышенности [7]. Густо расчлененная оврагами и балками, ступенчатая и многоярусная по рельефу, неоднородная по выходящим на поверхность горным породам Приволжская возвышенность отличается разнообразием ландшафта [11].

Для анализа правобережной части промышленного района добычи нефти важно подразделить территорию на 3 генетических типа местности:
1) долинный - распространен по долинам крупных рек. Возможность паводкового подъема уровня воды, а также эрозионные и оползневые процессы делают данный тип местности довольно неустойчивым к нефтяному загрязнению. В природном отношении к этому типу относится интразональная местность р. Медведицы, а также частично северостепная и лесостепная природные подзоны $[11,13]$. Здесь интенсивно протекают процессы плоскостной и линейной эрозии, оползнеобразования, что является показателем неустойчивости природной среды к антропогенным воздействиям [12]. Кроме того, для данного типа местности характерно, так же как и для пойменного, весеннее половодье, в период которого происходит интенсивное затопление территории с развитием благоприятных условий, способствующих быстрому проникновению нефти и нефтепродуктов в геологическую среду, инфильтрации в грунтовые воды.

2) склоновый тип характерен для склонов Приволжской возвышенности, оврагов и балок, уступов, спускающихся к Волгоградскому водохранилищу, а также склонов долин крупных рек. Он характеризуется повышенной активизацией процессов плоскостного смыва, линейной и боковой эрозии, осыпных и обвальных процессов [12]. В зависимости от крутизны и экспозиции склонов, а также климатических особенностей вышеперечисленные процессы могут проявляться с разной степенью интенсивности. Соответственно, данный тип местностей тоже можно отнести к неустойчивому. К нему относится большая часть месторождений района промышленной добычи нефти.

Склоновый тип местности наблюдается во всех ландшафтных районах Правобережья за исключением интразональных типов местности долин рек. Поэтому можно вести речь о том, что на степень устойчивости территории со склоновым типом местности к нефтяному загрязнению влияют 2 фактора: величина крутизны склонов (которая может способствовать активизации экзогенных процессов и, соответственно, приводить к увеличению возможности проявления геоэкологических рисков) и климатические условия (в особенности степень увлажненности территории), определяющие условия рассеивания и нейтрализации загрязняющих веществ в почвах, водных объектах и зоне аэрации. Избыточно влажная и влажная подзоны характеризуются преимущественным рассеиванием загрязняющих веществ, в недостаточно влажной подзоне могут иметь место как процессы рассеивания, так и накопления загрязнений, а в сухой подзоне всегда будут преобладать процессы концентрации загрязнителей или продуктов их нейтрализации [5]. На территории Правобережых районов промышленной добычи нефти засушливость климата возрастает по направлению с севера на юг. Следовательно, на территориях лесостепной зоны условия более 
благоприятны для рассеивания загрязняющих веществ, чем в типично степной зоне. Однако общее количество месторождений с типично степным ландшафтом больше, чем с северостепным и лесостепным. Поэтому можно данный тип местности подразделить исходя из ландшафтных особенностей на склоновый лесостепной - наиболее устойчивый к загрязнению среди склоновых типов местности, склоновый северостепной, обладающий устойчивостью к загрязнению, типично степной - менее устойчивый к загрязнению и склоновый приволжский подуступный - наименее устойчивый к загрязнению за счет больших уклонов и активизации абразионных, эрозионных и оползневых процессов.

3) приводораздельный тип - распространен в меньшей степени.

Такой тип местности отличается наибольшей устойчивостью к загрязнению ввиду глубокого залегания грунтовых вод (что исключает попадание в них загрязняющих веществ с земной поверхности), сменой при движении с северо-востока на юго-запад черноземов под богато-разнотравно-типчаково-ковыльными ассоциациями, оподзоленных черноземов под сельхозугодьями, обыкновенных черноземов под сельхозугодьями, маломощных малогумусных черноземов под разнотравно-типчаковоковыльными ассоциациями и южных солонцеватых черноземов под типчаково-ковыльными слабокомплексными ассоциациями [11].

Наиболее уязвимым с точки зрения устойчивости ландшафтов к нефтяному загрязнению является пойменный тип местности. Весеннее половодье, близость грунтовых вод, преобладающий механический состав почв и грунтов, уклон территории, активные оползневые и абразионные процессы, характерные в большей степени для правобережных участков, создают на поймах благоприятные условия для проникновения загрязняющих веществ в поверхностные и подземные воды.

Вторым по степени уязвимости типом местности является долинный, характерный для речных долин крупных и средних рек. Здесь интенсивно протекают процессы плоскостной и линейной эрозии, оползнеобразования, что является показателем неустойчивости природной среды к антропогенным воздействиям. Кроме того, для данного типа местности характерно, так же как и для пойменного, весеннее половодье, в период которого происходило интенсивное затопление территории с развитием благоприятных условий, способствующих быстрому проникновению нефти и нефтепродуктов в геологическую среду, инфильтрации в грунтовые воды.

Террасовый тип местности, выделяемый для палеотеррас Волги, относится к 3-му по степени уязвимости типу местности.
Следующим типом местности по уровню уязвимости является склоновый. Он характеризуется повышенной активизацией процессов плоскостного смыва, линейной и боковой эрозии, осыпных и обвальных процессов. В зависимости от крутизны и экспозиции склонов, а также климатических особенностей вышеперечисленные процессы могут проявляться с разной степенью интенсивности. Соответственно, данный тип местностей тоже можно отнести к неустойчивому.

Для приводораздельного типа местности характерно глубокое залегание грунтовых вод, что исключает попадание в них загрязняющих веществ с земной поверхности. Такой тип местности характеризуется слабой и средней степенью смытости и нередко эрозирован. Он может быть охарактеризован как относительно неустойчивый к загрязнению нефтью и нефтепродуктами.

Таким образом, рис. 1 служит своего рода районированием территории промышленной нефтедобычи Саратовской области по степени устойчивости к нефтяному загрязнению. Подобный мелкомасштабный уровень исследования позволяет сделать только общие выводы. Частные можно сделать на основе районирования территории в более крупном масштабе. При этом в пределах исследуемого района промышленной нефтедобычи становится возможным районирование территории по устойчивости к нефтяному загрязнению с более детальным подразделением типов местности в зависимости от особенностей их расположения в природных подзонах и разновысотного положения (рис. 2).

В зависимости от природной подзоны, к которой относится тот или иной тип местности, оказалось возможным провести районирование территории промышленной нефтедобычи по степени устойчивости к загрязнению нефтью в результате активизации геоэкологических рисков. Наличие разнообразных как по масштабу, так и по тематическому содержанию баз картографических данных и возможностей геонформационного картографирования позволило нам детально рассмотреть различные ситуации на нефтяных месторождениях Саратовской области. Это является ключом к дальнейшему созданию карт, отражающих различные аспекты геоэкологического риска эксплуатации месторождений и выработке на их основе рекомендация по дальнейшему природопользованию.

Важным фактором, оказавшим существенное влияние на создание картографического сопровождения данной статьи, явилось геоинформационное обеспечение процесса принятия решений при проведении районирования по степени устойчивости, а также при реализации картографической визуализации. 


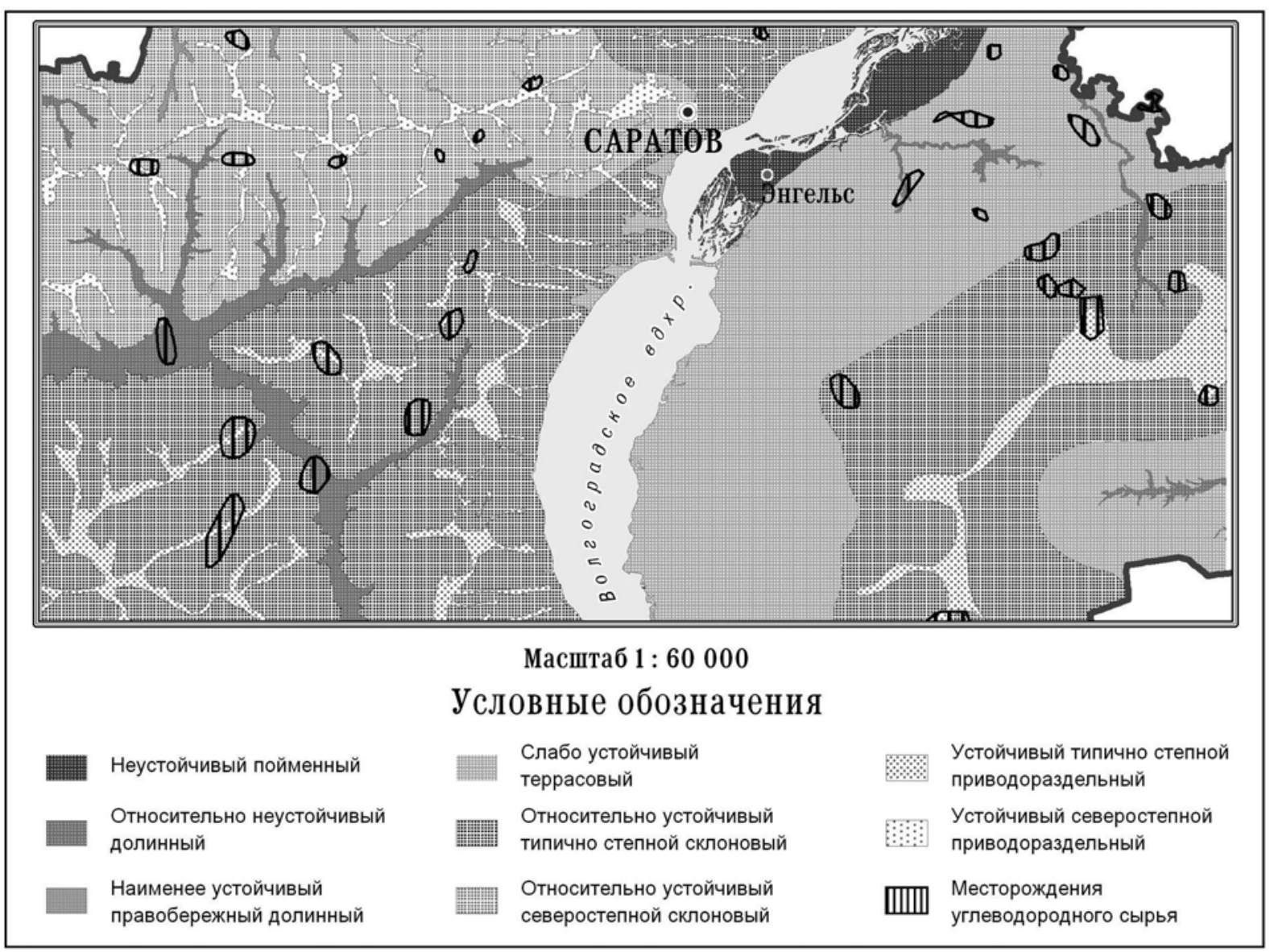

Рис. 2. Пример районирования части района промышленной добычи нефти по степени устойчивости к нефтяному загрязнению

\section{Библиографический список}

1. Министерство природных ресурсов РФ, федеральное унитарное геологическое предприятие «Волгагеология» Саратовская гидрогеологическая экспедиция // Инф. бюл. о состоянии недр на территории Приволжского федерального округа РФ (Саратовская область) за 2006 г. Саратов, 2007. Вып. 10.

2. Распутин A.B. ArcGIS - как инструмент моделирования аварийных разливов нефти // ArcReview. 2005. № 1(32). C. 24.

3. http://www.oilgasindustry.ru/?id=9488. -20.08 .2009 .

4. Схема территориального планирования Саратовской области. Отделение территориального проектирования ФГУП «ГИПРОГОР»: В 4 т. М., 2006. Т. 1. 130 с.

5. Мячина К.В., Чибилев А.А. Геоэкологческое районирование нефтегазоносной территории Оренбургской области // Поволж. экол. журн. 2005. № 2. С. 147-157.

6. Мазур И.И., Молдаванов О.И., Шишов В.Н. Курс инженерной экологии. М.: Высш. шк., 2001. 510 с.
7. Наумов А.Д., Ковальский Ф.И. Геоморфологическая карта Среднего и Нижнего Поволжья. Саратов, 1982.

8. Романов А.А., Ковальский Ф.И. Карта четвертичных отложений Среднего и Нижнего Поволжья. Саратов, 1982.

9. Востряков А.В., Ковальский В.И. Геология и полезные ископаемые Саратовской области. Саратов, 1986. 127 с.

10. Макаров В.3., Пестряков А.К. Ландшафтная структура Саратовской области // География Сар. обл. Саратов, 1996. C. 53-68.

11. Особо охраняемые природные территории Саратовской области / Под ред. В. З. Макарова. Саратов, 2007. 300 с.

12. Лотоикий Г.И., Зайони В.Н. Опасные процессы современного геоморфогенеза в Саратовском Поволжье // Изв. Сарат. ун-та. Нов. сер. 2007. Т. 7. Сер. Науки о Земле, вып. 2. С. 14-16.

13. Макаров В.3. Карта «Ландшафтное районирование Саратовской области» // Эколого-ресурсный атлас Саратовской области. Саратов, 1996. С. 7.

14. Солнцева Н.П. Добыча нефти и геохимия природных ландшафтов. М., 1998. 376 с. 